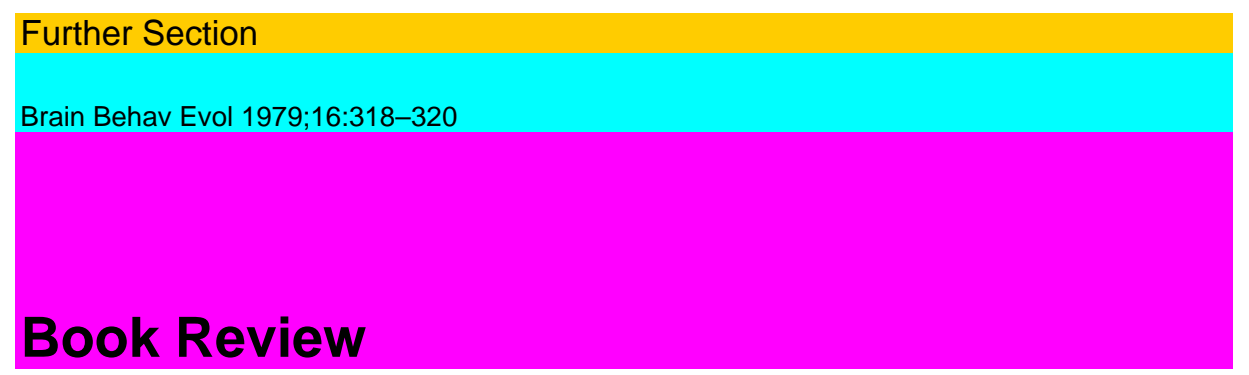

\title{
S. J. Gould
}

Ontogeny and Phytogeny

Harvard University Press/Belknap, Cambridge, Mass. 1977501 pp., 71 fig.; US \$ 18.50 ISBN 0-674-63940-5

Why do early embryos of all vertebrates look so alike? Why do human embryos share certain features and developmental processes with those of fish? Do the early stages of ontogeny of creatures now living, reflect or recapitulate the stages through which our adult procreative ancestors passed in their evolutionary histories? Are there common processes at work in the ontogeny of living vertebrates and the phy-logenetic development of their ancestors? Stephen Gould describes and explains the basic processes that led to the evolution of increasingly complex creatures, especially of ourselves. The biogenetic 'law' of 'ontogeny recapitulates phylogeny' was once believed rescinded as a valid conception of why some sequences or' development in form during ontogeny seem to parallel or 'mimic' many of those found in the phylogeny of ancestral lineages. Gould shows how this idea still has elements of 'truth' and that its abandonment was due more to historical alterations in viewpoint, interest and subject matter than to logical or experimental disproof. He provides insights into processes and mechanisms now believed to operate in ontogeny and phylogeny, and of how to correctly conceive and explain the occurrence of ancestral-like structural features in particular phases of ontogenetic development of individuals.

Book Review

319

In the first major section of the book, Gould tells an exciting story of these conceptual achievements and about the evolution of controversies that paralleled them. He describes these conflicts, their sources, and the historical development of our understanding of multiple interrelated evolutionary and developmental processes. Gould invites us to dwell within the labyrinths of over a century of controversial thought, observation and experiment dealing with these most basic of biological issues of natural history which first sparked the curious minds of the 19th century. For it was those minds that created the first comprehensive conceptions of interrelationships of humans and mammals, of mammals and vertebrates, of vertebrates and all animal life, of the fauna and flora, and of all these rooted and bound to the earth, its waters and atmosphere. These were the decades of a great ferment and flowering of human intellectual discovery; the days of the earliest comprehensive rational thought about natural history. The fascination of this book is that Gould has succinctly traced for us the discourse, arguments and thinking patterns of these natural philosophers on such broad-ranging phenomena. To do this, he states each major conceptual issue, then produces the most pertinent quotations from the writings of those individuals involved, followed by Gould's own, modernized, rephrasing of the cited ideas; paraphrased so carefully and sensitively, as if he had revived the early writer once again to active dialogue, but in modern tongue. This section of the book is a most impressive and scholarly historical essay. It is a thorough and nicely documented conceptual review of historical controversies about the mechanisms and relationships between ontogeny and phylogeny. Gould's re-examination and analysis of these neglected issues should settle, once and for all, these conflicting viewpoints, never really resolved, that once seemed to be at odds with one another. 
In the course of this historical section, Gould reveals important facets about modes of thought of scientists: the influence of political, social and cultural concepts of the times on scientific thinking; the reverse influences of scientific discoveries and theories on lay thought, public institutions and political ideology; the subtle, but powerful, metaphysical influences on creative imagination when needed facts are technically still not obtainable; the power of preconception to promote dogmatic acceptance of particular words, meanings and viewpoints; the persuasive potency of metaphor; the difficulty of devising adequate definitions that can capture the everchanging and dynamic flow of complex interacting natural phenomena.

Having set and played the stage with drama and narrative about ideas of ontogeny and phylogeny, Gould launches the second major section of his book with his own synthesis of data and concepts (both past and present) about ontogeny and phylogeny. He examines those basic processes common to ontogeny and phylogeny. This extensive, thoroughly researched portion of his book is an interdisciplinary attempt to propose a relatively simple scheme by which to view the major underlying processes that have led to the evolution of a great diversity of living creatures, each with its unique sets of adaptive life strategies. He carefully defines the concepts of 'heterochrony', 'paedomorphosis' ,'progenesis', and 'neoteny', derived from numerous studies of form and function both in the evolution of ancestral lineages and in the development of living animals descendent from these lineages. He has carefully articulated and documented how these evolutionary processes differentially reveal Book Review

320

themselves in the ontogenetic development of individuals in each species. He shows how successions of genetically altered ontogenies result in micro- and macroevolu-tionary changes. He ends this major contribution by revealing how these basic processes have yielded up the advances in primates that culminated in the genus Homo.

Throughout both the historical and modern synthetic sections of this book, Gould introduces us to a great variety of terms that have been used to describe the basic phylogenetic and ontogenetic events, trends and processes. He shows how the meanings of these terms have been altered historically, and he clarifies their definitions from current vantage points.

Gould's last few chapters on the heterochronic changes that have occurred during primate evolution are beautifully and forcefully written. They are of interest to all biologists, regardless of subdiscipline, who are interested in human complexity and its evolutionary and developmental sources. This is a very important treatise that should help biologists grasp a unified evolutionary-developmental conceptual framework that has authenticity in fact and experiment. It brings together an impressive number of different, but related viewpoints from paleontology, evolutionary biology, ethology and psychology, ecology, anatomy, embryology, psychoanalysis, politics, education, population genetics, art, humor and poetry to document the history of lay and scientific thought about the important relationships between ontogeny and phylogeny.

The book is carefully and logically organized; thoroughly outlined and indexed. References to the literature are always relevant and in context. Quotations are superbly pertinent, data (graphic, tabular and written) are ample, and support all arguments. Summaries of all sections, concise and beautifully written, are interspersed throughout the text as well as in the 'Prospectus' and 'Epitome', at the beginning. The Epilogue summarizes Gould's strategies and viewpoints, main purposes and problems, and bis major conclusions. The extensive notes at the end, indexed to lines in the text by superscripts, are useful 'asides' that elaborate on important issues dealt with in the text.

L. Like any work of art in this elegant work Stephen Gould displays his articulateperception of some important issues regarding fundamental biological phenomena.He does this with a skillful blend of analysis and synthesis. His love for the historyof ideas can be felt and almost tasted. He employs superb rhetoric

eloquent metaphor

sensitive insights

humaneness

unusual objectivity 
and balanced perspective,a delicate balance of humor and wit.

Wally Welker

Madison

Wise. 